\title{
The Dynamic Behavior of Different Hollow Flexible Robot's Arms
}

\author{
Dr. Saad Zaghlul Saeed \\ Mechatronics Eng. Dept.
}

Bakr Noori Alhasan

Mechanical Eng. Dept.

Mosul University

\section{Abstract}

In this paper, four different shapes of robots' hollow arm are suggested so as to investigate the effect of shape on the dynamic behavior of the arm. The finite element method is used to determine the strength of the arms and their equations of motion. The static deflection, stress and moment of inertia are calculated and compared as well as the angular displacement and tip vibration of the four different shapes.

A PD controller with fuzzy logic is used for tracing the desired trajectory and reducing the overshoot of the system. All simulations were presented using MATLAB and SIMULINK on the arms under the same desired step trajectory for a time of two seconds. The preferred robot arm is the one that has less vibration in trajectory and after reaching the target. As a result, the tapered arm (shape B) shows better characteristics in which less deflection, stress and tracking.

Key Words: Robot arm, Finite element, Flexible link, Fuzzy controller.

$$
\text { السلوك الديناميكي لأذرع روبوت مجوفة ومرنة مختلفة الثكل }
$$

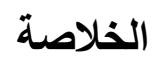

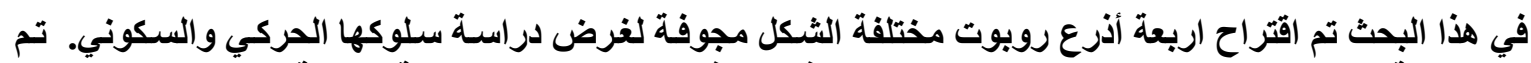

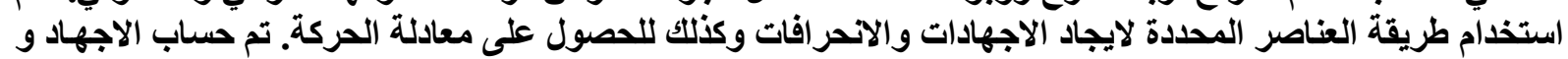

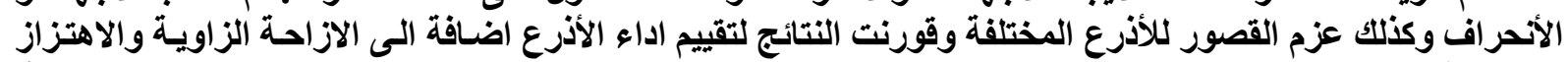

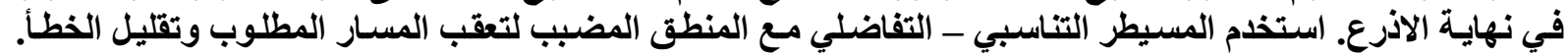

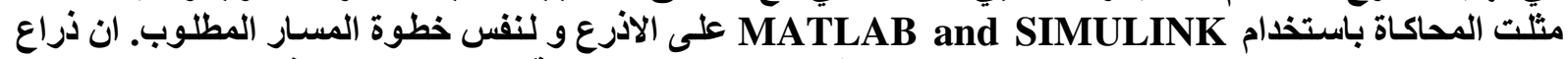

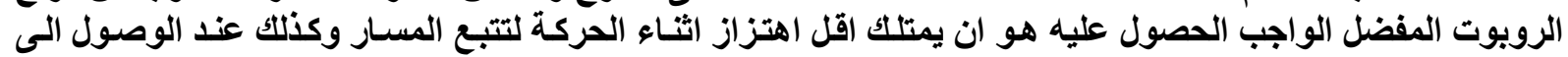

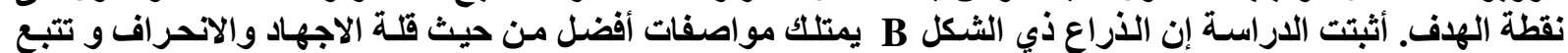

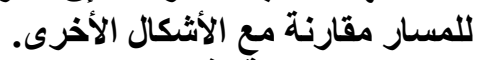
الكلمات المفتاحية: ذراع رويوت، العناصر المحددة،الذراع المرن، المسيطر المضبب. 


\section{Introduction}

Robotic manipulation tasks are becoming more demanding as the potential for such manipulators to complete these tasks is realized. Industrial robot manipulators of high accuracy require complicated methods of control. Flexible robot manipulators exhibit many advantages over rigid robots: they require less material, lighter in weight, consume less power, require smaller actuators, have less overall cost and higher payload to robot weight ratio. Problems arise due to precise positioning requirements, system flexibility which leads to vibration [1,2].

Various approaches have been developed previously for modeling of flexible manipulators. These can be divided into two main categories: the assumed modes method (AMM) and the numerical analysis approach. Using the assumed modes approach, a control method at terminal stage of movement has been developed and engaged with PID in [4]. Numerical analysis techniques include finite difference (FD) and finite element (FE) methods. The performance of the FE technique in modeling of flexible manipulators has previously been investigated [5]. It has been reported that in using the FE method, a single element is sufficient to describe the dynamic behavior of a flexible manipulator reasonably well. Simulation and experimental results of the response of flexible manipulator were presented in [6].

In the control of flexible link robot manipulator, a variety of control techniques are popular, such as PID control, computed torque control, adaptive control etc. Recently, intelligent controllers have been used to control robot manipulators [7]. Composite controller using neural network plus Fuzzy PD feedback is used to control multi-link flexible manipulator as in [8].
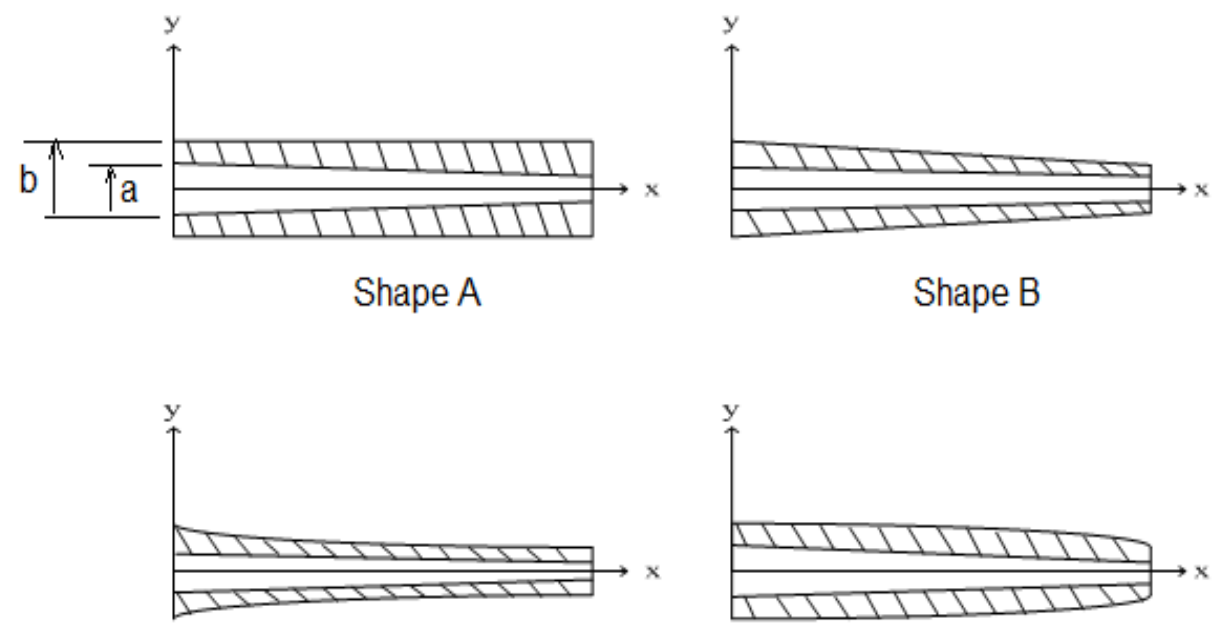

Shape C

Shape D

Figure (1) Four different shapes of robot's arm

In the present work four different shapes of robot's arm are suggested and investigated (Fig. (1)). The cross-sectional area of three of them is assumed to be a function of the length. The investigation includes calculating the strength of the arms and their dynamic response to input torque. The finite element method is used to discretize the equations of motion and to model the different shapes of robot's arm. Fuzzy supervisor for PD controller is used for trajectory tracking. 


\section{2-Finite Element Analysis}

\subsection{Static Analysis}

In this study, the stresses and deflections are found with the Ansys software package version 14. The stress and deflection of the arm are calculated under the effect of its own weight. For Shape A (Fig. 1), the cross sectional area is considered constant; while for the other three as a function of length. The maximum cross sectional area $\left(\mathrm{A}_{\max }=0.00012 \mathrm{~m}^{2}\right)$ is at the fixed end; while the minimum $\left(\mathrm{A}_{\min }=0.00006 \mathrm{~m}^{2}\right)$ is at the free end. The arm's width is assumed constant and equals to $0.02 \mathrm{~m}$. The arms are assumed to be made of aluminum having the following material characteristics: density, $\rho=2710 \mathrm{~kg} / \mathrm{m}^{3}$; Modulus of elasticity, $\mathrm{E}=71.109$ MPa; Length, $l=1 \mathrm{~m}$. Also $\mathrm{a}=0.003 \mathrm{~m} ; \mathrm{b}=0.0015 \mathrm{~m}$. The maximum stress $\left(\sigma_{\max }\right)$, maximum deflection $\left(\delta_{\max }\right)$, and mass moment of inertia $\left(\mathrm{I}_{\mathrm{b}}\right)$ are calculated and presented in table (1). Maximum stress is developed in shape A and D, while the minimum is developed in shape B. Also comparison study of deflection shows that the maximum value is obtained in shape $\mathrm{C}$, while minimum value is in shape $\mathrm{D}$.

Although the above strength test gave a useful information, but for flexible robots arm the dynamic behavior is very important. Thus the dynamic analysis is used to model these different arm's shapes.

Table (1) Results of static loading comparisons for different arm's shapes.

\begin{tabular}{|c|c|c|c|c|}
\hline Shape & $\sigma_{\max } \mathrm{MPa}$ & $\delta_{\max }(\mathrm{m})$ & Function & $\mathrm{I}_{\mathrm{b}}\left(\mathrm{kg} \cdot \mathrm{m}^{2}\right)$ \\
\hline $\mathrm{A}$ & 19.2 & 0.0125 & $\mathrm{y}(\mathrm{x})=\mathrm{a}$ & 0.08943 \\
\hline $\mathrm{B}$ & 11.4 & 0.01132 & $\mathrm{y}(\mathrm{x})=\mathrm{a}-\mathrm{b} \cdot(\mathrm{x} / \mathrm{L})$ & 0.05589 \\
\hline $\mathrm{C}$ & 14.5 & 0.0204 & $\mathrm{y}(\mathrm{x})=\mathrm{a}-\mathrm{b} \cdot(\mathrm{x} / \mathrm{L})^{1 / 2}$ & 0.05101 \\
\hline $\mathrm{D}$ & 19.8 & 0.01008 & $\mathrm{y}(\mathrm{x})=\mathrm{a}-\mathrm{b} \cdot(\mathrm{x} / \mathrm{L})^{2}$ & 0.06260 \\
\hline
\end{tabular}

\subsection{The dynamic Analysis}

The flexible arm as shown in Fig. 2 is considered clamped at the hub. The Bernoulli-Euler beam theory is used to model the elastic behavior of the manipulator. Considering linear displacements, the total displacement $\mathrm{y}(\mathrm{x}, \mathrm{t})$ at a distance $\mathrm{x}$ from the frame origin in the OX direction can be described as a function of both the rigid body motion $\theta(\mathrm{t})$ and elastic deflection $\mathrm{v}(\mathrm{x}, \mathrm{t})$ as:

$y(x, t)=x \cdot \theta+v(x, t)$

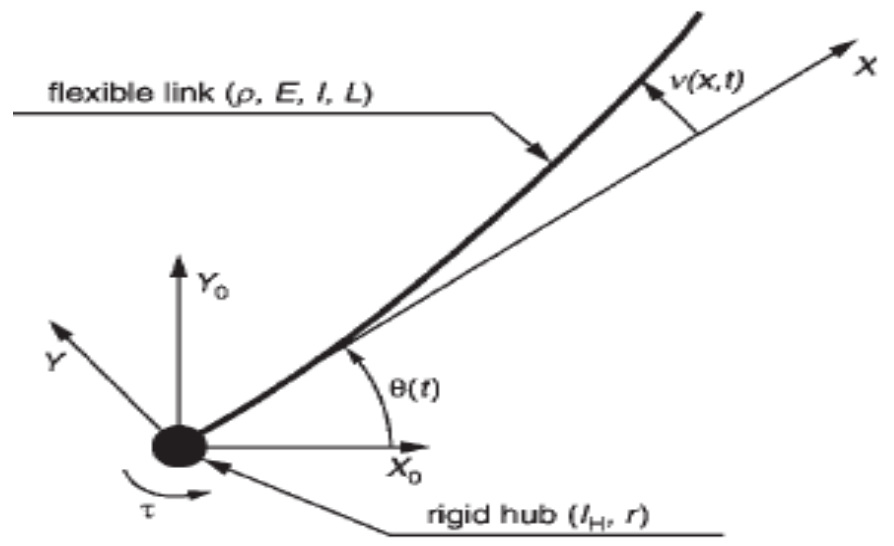

Using the standard FE method to solve dynamic problems, leads to Figure (2) Mechanical model of a single flexible arm the well known equation:

$$
\mathrm{v}(\mathrm{x}, \mathrm{t})=\sigma_{\mathrm{a}}(\mathrm{x}) \cdot \mathrm{Q}_{\mathrm{a}}(\mathrm{t})
$$

where $\sigma_{\mathrm{a}}(\mathrm{x})$ and $\mathrm{Q}_{\mathrm{a}}(\mathrm{t})$ represents the shape function and nodal displacement respectively. 
The arm is approximated by partitioning it into k elements. As a consequence of using the Bernoulli-Euler beam theory, the FE method requires each node to possess two degrees of freedom, a transverse deflection and a rotation. These necessitate the use of Hermit cubic basis functions as the element shape function [9]. Hence, for the elemental length $l$, the shape function can be obtained as:

$$
\sigma_{\mathrm{a}}=\left[\begin{array}{llll}
\varphi_{1}(\mathrm{x}) & \varphi_{2}(\mathrm{x}) & \varphi_{3}(\mathrm{x}) & \varphi_{4}(\mathrm{x})
\end{array}\right]
$$

where

$$
\begin{aligned}
& \varphi_{1}(\mathrm{x})=1-\frac{3 \mathrm{x}^{2}}{1^{2}}+\frac{2 \mathrm{x}^{3}}{1^{3}} \quad \varphi_{2}(\mathrm{x})=\mathrm{x}-\frac{2 \mathrm{x}^{2}}{1}+\frac{\mathrm{x}^{3}}{1^{2}} \\
& \varphi_{3}(\mathrm{x})=\frac{3 \mathrm{x}^{2}}{1^{2}}-\frac{2 \mathrm{x}^{3}}{1^{3}} \quad \varphi_{4}(\mathrm{x})=\frac{\mathrm{x}^{2}}{1}+\frac{\mathrm{x}^{3}}{1^{2}}
\end{aligned}
$$

For element $\mathrm{k}$ the nodal displacement vector is given as:

$\mathrm{Q}_{\mathrm{a}}=\left[\begin{array}{llll}\mathrm{v}_{\mathrm{k}-1}(\mathrm{t}) & \theta_{\mathrm{k}-1}(\mathrm{t}) & \mathrm{v}_{\mathrm{k}}(\mathrm{t}) & \theta_{\mathrm{k}}(\mathrm{t})\end{array}\right]$

where $\mathrm{v}_{\mathrm{k}-1}(\mathrm{t})$ and $\mathrm{v}_{\mathrm{k}}(\mathrm{t})$ are the elastic deflections of the element and $\theta_{\mathrm{k}-1}$ and $\theta_{\mathrm{k}(\mathrm{t})}$ are the corresponding rotations. Substituting for $\mathrm{v}(\mathrm{x}, \mathrm{t})$ from (2) into (1) and simplifying yields:

$$
y(x, t)=\sigma(x) \cdot Q(t)
$$

where

$$
\sigma(\mathrm{x})=\left[\begin{array}{ll}
\mathrm{x} & \sigma_{\mathrm{a}}(\mathrm{x})
\end{array}\right] \text { and } \quad \mathrm{Q}(\mathrm{t})=\left[\begin{array}{ll}
\theta(\mathrm{t}) & \mathrm{Q}_{\mathrm{a}}(\mathrm{t})
\end{array}\right]^{T}
$$

The new shape functions $\sigma(\mathrm{x})$ and nodal displacement vector $\mathrm{Q}(\mathrm{t})$ in $(3)$ incorporate local and global variables. Among these, the angle $\theta(t)$ and the distance $x$ are global variables while $\sigma_{\mathrm{a}}(\mathrm{x})$ and $\mathrm{Q}_{\mathrm{a}}(\mathrm{t})$ are local variables. Defining

$$
\mathrm{s}=\mathrm{X}-\sum_{\mathrm{i}=1}^{\mathrm{k}-1} 1_{\mathrm{i}}
$$

as a local variable of the $\mathrm{k}^{\text {th }}$ element, where $l_{\mathrm{i}}$ is the length of the $\mathrm{i}^{\text {th }}$ element, the kinetic energy of an element $\mathrm{k}$ can be expressed as:

$$
\mathrm{T}_{\mathrm{k}}=\frac{1}{2} \int_{0}^{1} \rho \mathrm{A}(\mathrm{s})\left[\frac{\partial \mathrm{y}(\mathrm{s}, \mathrm{t})}{\partial \mathrm{t}}\right]^{2} \mathrm{ds}=\frac{1}{2} \dot{\mathrm{Q}}^{\mathrm{T}}\left[\int_{0}^{1} \rho \mathrm{A}(\mathrm{s})\left(\sigma^{\mathrm{T}} \sigma\right) \mathrm{ds}\right] \dot{\mathrm{Q}}
$$

where $\mathrm{A}(\mathrm{s})$ is the cross-sectional area of the beam. The potential energy of the element can be obtained as:

$$
\begin{aligned}
V_{k} & =\frac{1}{2} \int_{0}^{1} E I\left[\frac{\partial^{2} y(s, t)}{\partial s^{2}}\right]^{2} d s=\frac{1}{2} \int_{0}^{1} E I\left(\frac{d^{2} \sigma}{d s^{2}} Q\right)^{T}\left(\frac{d^{2} \sigma}{d s^{2}} Q\right) d s \\
& =\frac{1}{2} Q^{T}\left[\int_{0}^{1} E I\left(\frac{d^{2} \sigma}{d s^{2}}\right)^{T}\left(\frac{d^{2} \sigma}{d s^{2}}\right) d s\right] Q .
\end{aligned}
$$


Using the Lagrange equation after assembling the element mass and stiffness matrices, the dynamic equations of motion of the flexible manipulator can be obtained as:

$$
M \ddot{Q}(\mathrm{t})+K Q(\mathrm{t})=f(\mathrm{t})
$$

where $\mathrm{M}$ and $\mathrm{K}$ are global mass and stiffness matrices of the manipulator respectively, and $f$ is vector of external forces. For more details about the derivation of these matrices see [6].

\section{3-Fuzzy Logic Controller}

A fuzzy logic controller can be regarded as an expert system with a knowledge representation based on the use of fuzzy set description. It has a collection of rules which are stored in a knowledge base, that express how the system parameters vary as input is varied in a linguistic form. The design of a fuzzy controller involves the following steps: a definition of controller structure, the acquisition and representation of knowledge or rule base, and the design / analysis of the controller. A synoptic of Fuzzy Logic Controller which is made of three components: the knowledge or rule base, reasoning / inference mechanism and input / output interface [10]. Knowledge or rule base comprises of cognition of application domain and the desired output response. It consists of a data base and fuzzy control rule base which characterizes the desired output response applied by the operative by means of a set of control rules. The rules use a linguistic description based on expert knowledge.

\subsection{Fuzzy Supervisor for PD}

The objective of the fuzzy supervisor is to gradually increase the proportional and derivative gains of the controller, as the system error approaches zero, so as to improve the response of the system. A general block diagram of a fuzzy supervised system is shown in Fig. 3. System control is still accomplished by the ZieglarNicolas tuned controller, however, the gain values $K_{P}$ and $K_{D}$ are now controlled by the FLS (fuzzy logic supervisor). The general structure of the FLS is similar to that of the FLC. The differences are in the rule base and the supervisor outputs [11]. The supervisor outputs $\left(\Delta \mathrm{K}_{\mathrm{P}}\right.$ and $\left.\Delta \mathrm{K}_{\mathrm{D}}\right)$ are the incremental changes to be made to the existing parameters.

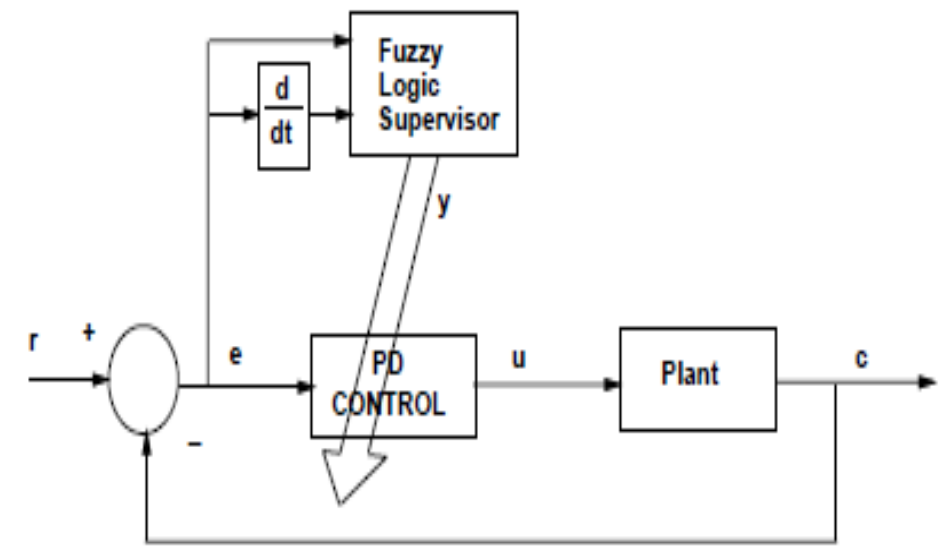

Figure (3) PD control with fuzzy supervisor

While the basic operation of the fuzzy supervisor is similar to that of an FLC, it's not designed to provide incremental changes based on how a human would operate the system. For conventional PD fuzzy controllers, that a gradual increase in the proportional gain as system error decreases, reduces the overshoot of the system. This concept is used for the design of fuzzy supervisor. The development of the supervisor control matrix is based on the observation of a typical step response shown in Fig. 4 below. The step response is divided into four general regions, each determined by the sign of the error and change in error. The regions are: Region1: positive error, negative change in error. Region2: negative error, negative change in 
error. Region3: negative error, positive change in error. Region4: positive error, positive change in error. Region5: (the zero region) is used when both the error and change in error values are near zero and it's not dependent on the sign of the signals. The resultant supervisor control matrix is shown in Table 2. A total of nine membership functions for both input and output signals are used. The membership functions are described as NL (negative large), NB (negative big), NM (negative medium), Ns (negative small), ZO (zero), PS (positive small), PM (positive medium), PB (positive big), and PL (positive large).

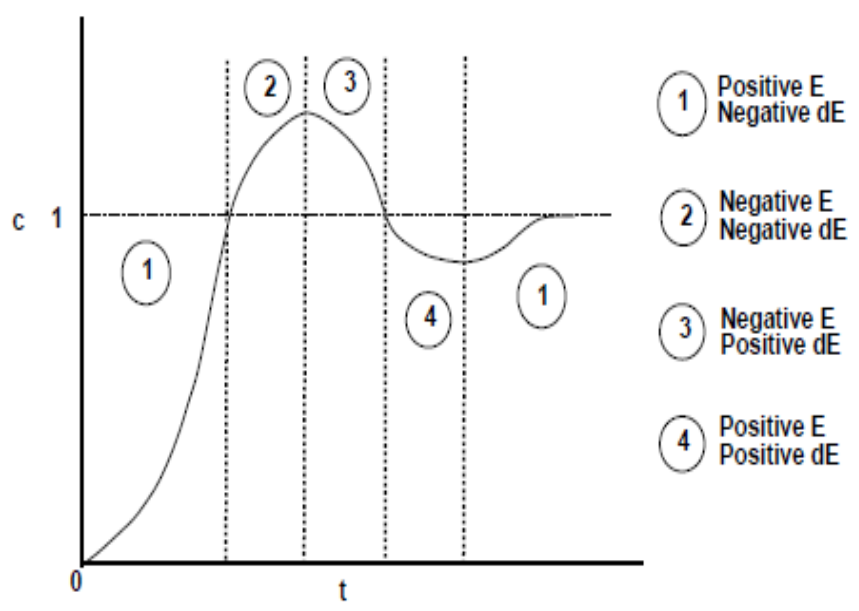

Figure (4) typical step response

Using the supervisor output (y), the incremental changes are calculated as

$\Delta K_{P}=y \cdot K p$ and $\Delta K_{D}=y \cdot K_{D}$

Equation (4) ensures that the original ratio is maintained.

Table 2: Fuzzy Supervisor rule Matrix

\begin{tabular}{|c|c|c|c|c|c|c|c|c|c|}
\hline$\Delta \mathrm{e} \backslash \mathrm{e}$ & NL & NB & NM & NS & ZO & PS & PM & PB & PL \\
\hline NL & NL & NL & NL & NL & PB & PB & PB & PM & PM \\
\hline NB & NL & NL & NL & NB & PB & PB & PB & PM & PM \\
\hline NM & NL & NL & NB & NM & PB & PB & PM & PM & PS \\
\hline NS & NL & NB & NM & NS & PL & PB & PM & PS & PS \\
\hline ZO & ZO & NS & NM & NB & PL & PB & PM & PS & ZO \\
\hline PS & PS & PS & PM & PB & NL & NS & NM & NB & NL \\
\hline PM & PS & PM & PM & PB & NB & NM & NB & NL & NL \\
\hline PB & PM & PM & PB & PB & NB & NB & NL & NL & NL \\
\hline PL & PM & PM & PB & PB & NB & NL & NL & NL & NL \\
\hline
\end{tabular}

\section{4- Dynamic Simulation of Arm's Shapes}

In order to illustrate the performance of the different arm's shapes, the four arms are subjected to the same desired step trajectory during a time of two seconds. These different shapes are chosen with respect to material economic purposes and reducing in moment of inertias. A PD controller with fuzzy supervisor is used for tracing the desired trajectory. All simulations were presented using MATLAB and SIMULINK, which are used widely in control applications. The time step size used in simulation is 0.001 second. $P D$ gains are: $K_{P}=45$ and $K_{D}=$ 10.

Figs. (5\&6) show comparisons of the hub angular displacement and end-point vibration responses for the four different arm's shapes respectively. As expected, vibration exists along the trajectory and after reaching the end point of motion because the hub angular position is used in the feedback error signal. This will let the arm vibrate under base acceleration freely 
which shows the dynamic behavior of these different arms. Five elements are used to discrete the arm which describes the first two modes to high accuracy [6]. A large oscillation in the hub and tip motion appears in Shape A due to the high inertial effects (see Table (1)). The tapered arm - shape B - presents less vibration during trajectory and after reaching the end point of motion. In shape $\mathrm{C}$, the vibration is more than that of shape $\mathrm{B}$ as the moment of inertia of this arm is less in comparison to that of the other three shapes. Shape D presents less vibration in comparison to the three other shapes though this shape has higher moment of inertia.
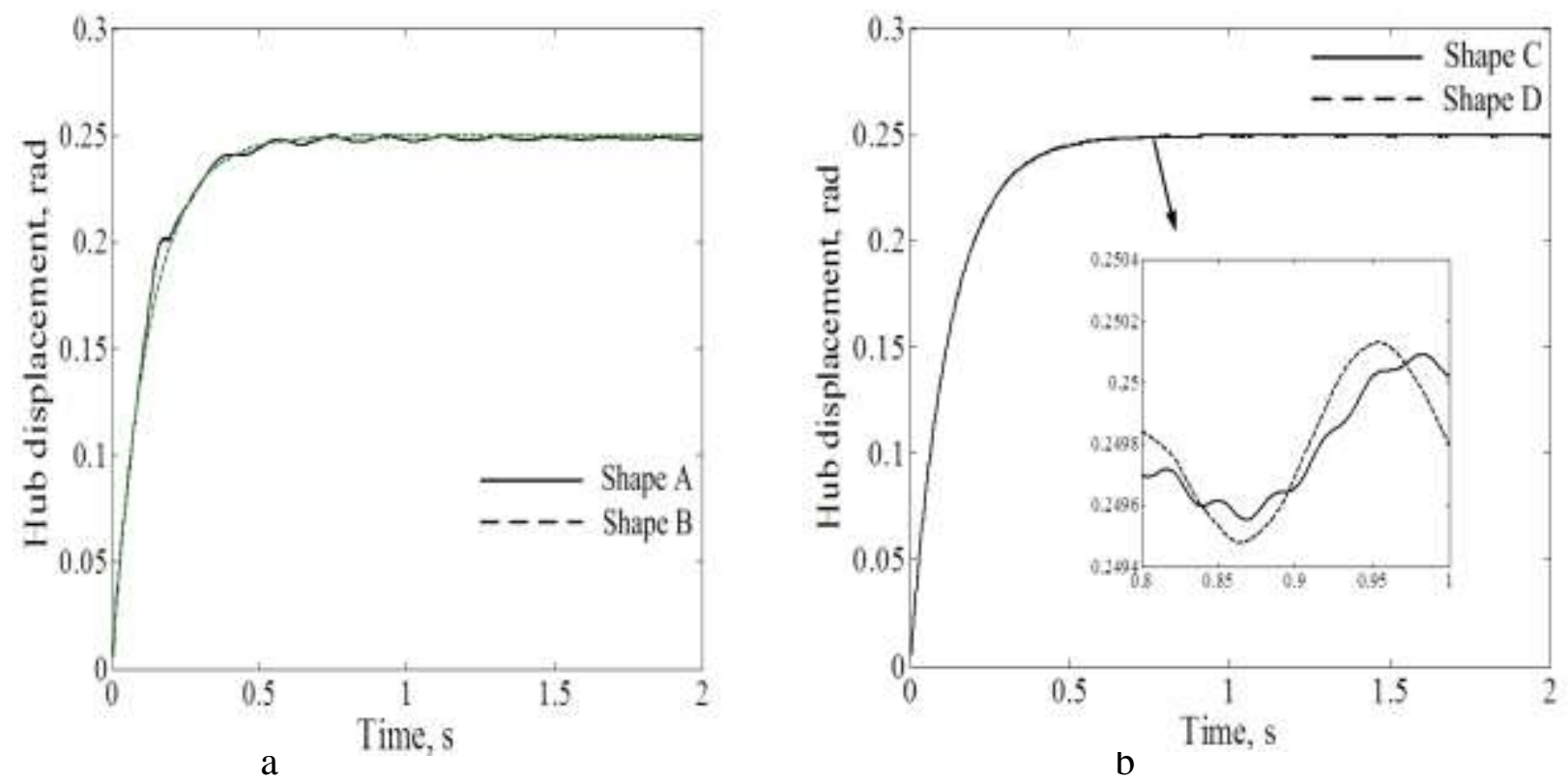

Figure (5) Hub angular displacement of the four different arm's shapes

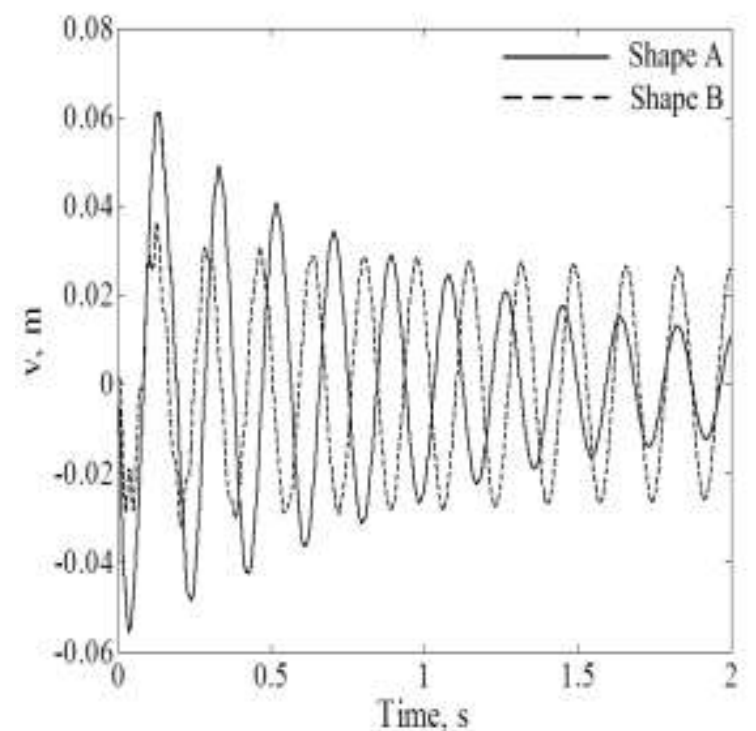

a

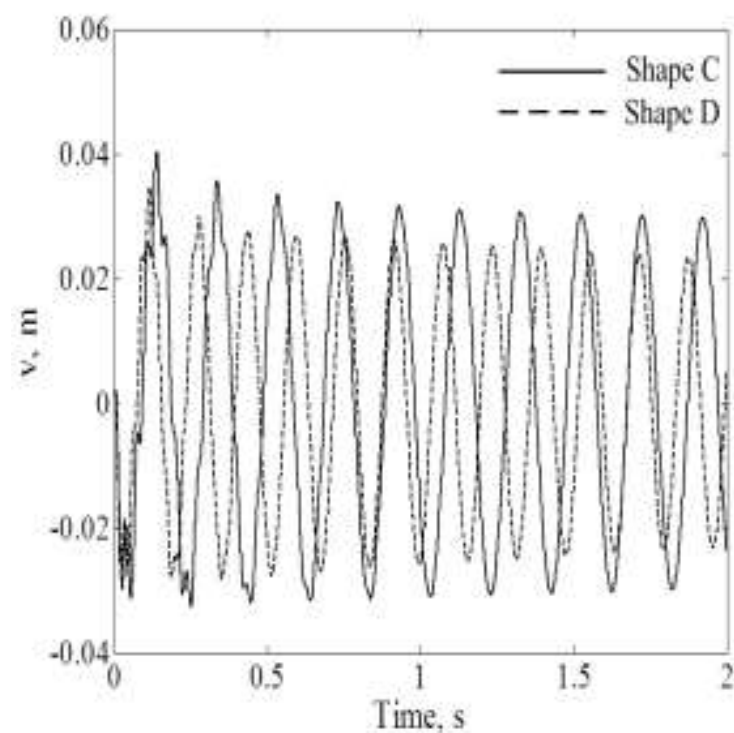

b

Figure (6) Tip vibration of the four different arm's shapes 
Then another comparison is made in which the moment of inertia for all the shapes is taken a fixed value case. The value of moment of inertia for shape $\mathrm{C}$ is used as a reference. Fluctuation of shape A hub's displacement becomes less as shown in Fig. 7. Also from Fig. 8 , the tip vibration is reduced for shape A. The attenuation for shape A is higher while the effect is very small for the other three shapes. This attenuation is due to the action of the controller through the coupling between the flexible arm of shape A and its hub.

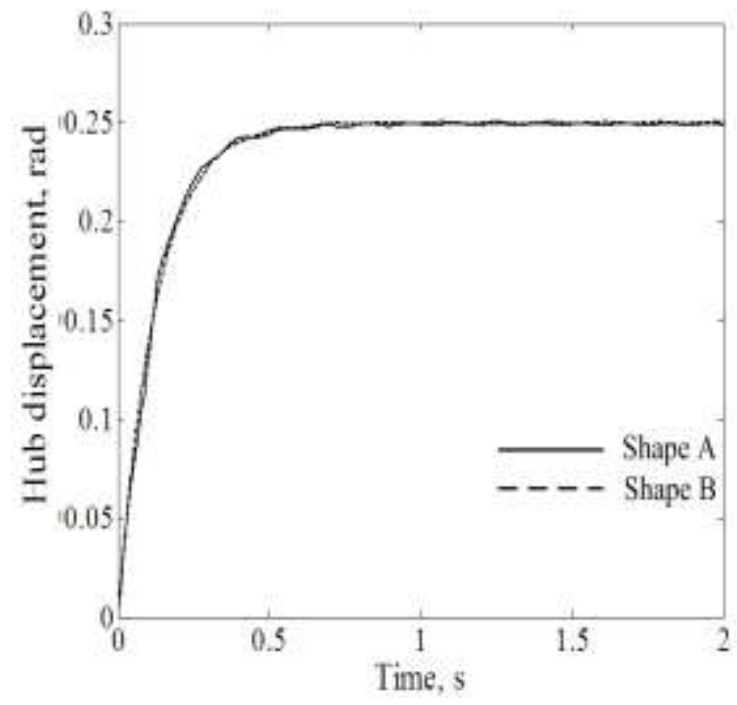

a

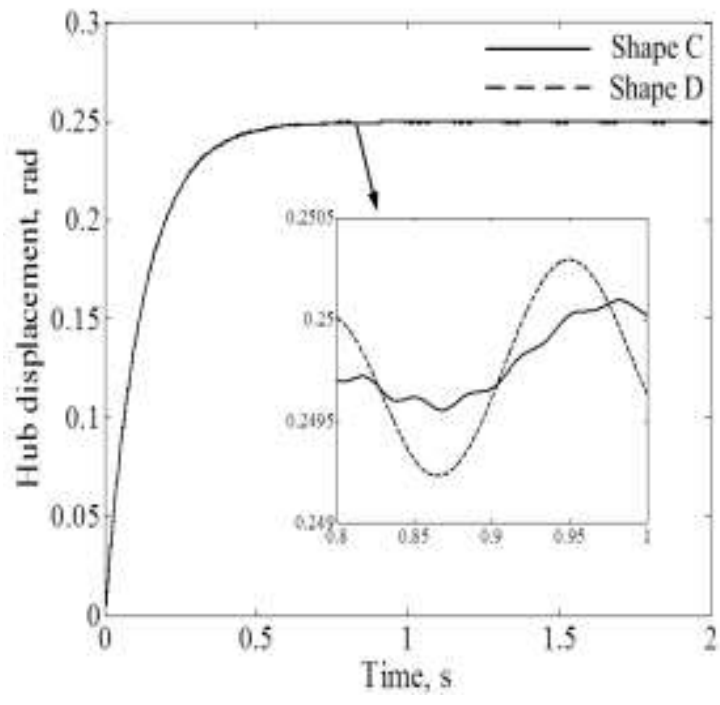

$\mathrm{b}$

Figure (7) Hub angular displacement of the four different arm's shapes

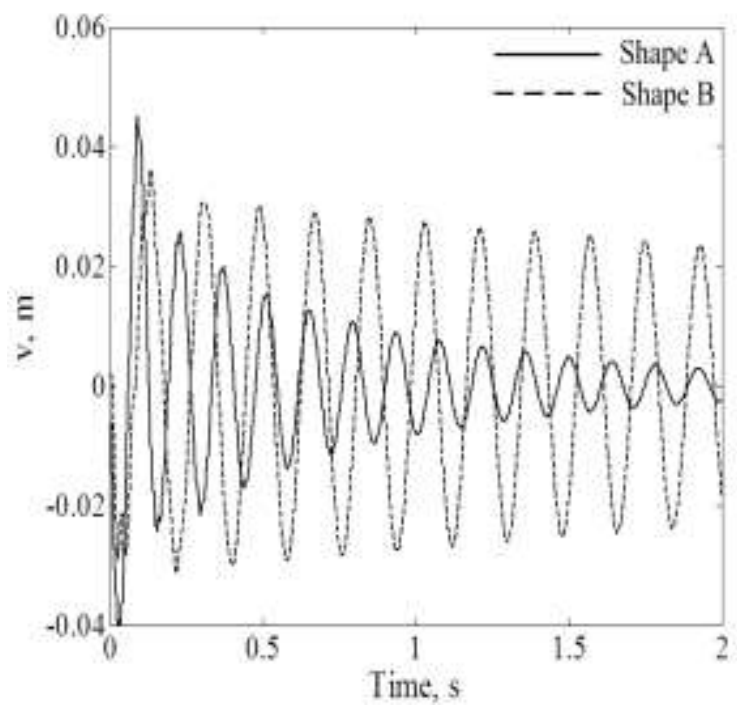

a

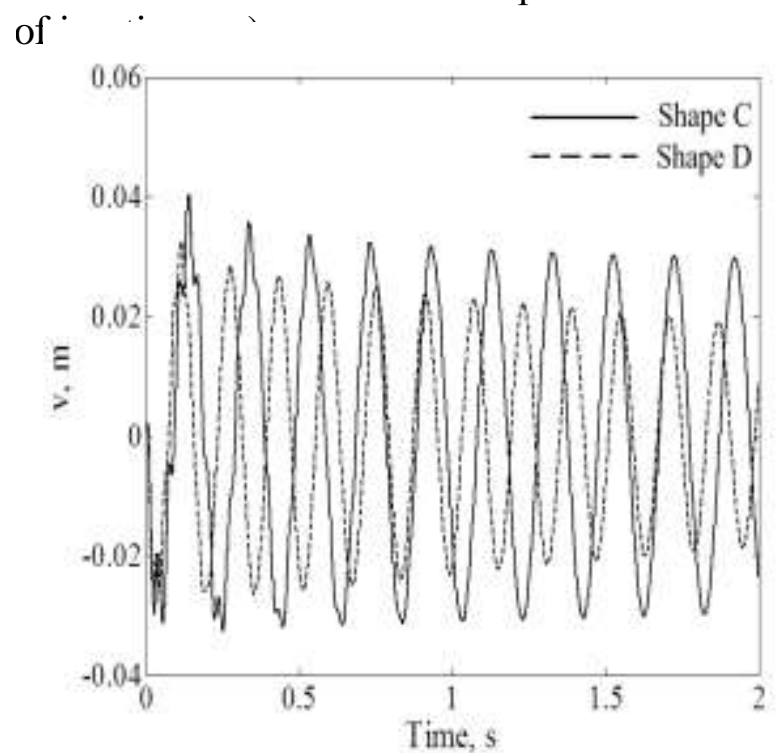

b

Figure (8) Tip vibration of the four different arm's shapes (constant moment of inertia case) 


\section{5-Conclusion}

The strength and dynamic behavior are different for the four tested shapes. The arm of shape B has less displacement fluctuation effect on the hub and small tip vibration in comparison to the other three arm's shapes. For the case of constant moment of inertia, the tip vibration of shape A is quickly attenuated than before; but it stills has fluctuation on hub's displacement due to its inertia. The small fluctuation on hub's angular displacement and tip vibration amplitude makes the arm of shape B has better dynamic behavior. This tapered shape arm will improve the trajectory tracking and reduce the size of the driver which makes the actual motion of the flexible arm resembles that of a rigid arm.

\section{Acknowledgment}

The authors appreciate Dr. Zakariya Yahya Mohammed comments and suggestions which have significantly improved the presentation of the paper.

\section{References}

1. Modeling and Control of Flexible Manipulators - Revisited / J. C. Piedboeuf, M. Farooq, M.M. Bayoumi, G. Labinaz, M.B. Argoun // Proc. 36th Midwest Symp. on Circuits and systems. - Detroit, 1993. - P. 1480-1483.

2. Саад Загхлюл С. Ал-Каиит. Робот-манипулятор с модифицированными динамическими характеристиками // Известия вузов. Сев.-Кавк. регион. Спец. выпуск: Проблемы мехатроники - 2006. -2007. - С.62-66.

3. Лукьянов А. А. Отслеживание траектории пространственными гибкими манипуляторами с помощью решения обратной задачи кинематики и гашения колебаний // Мехатроника, автоматизация, управление. - 2004. - № 11. - С. 23-29.

4. Санкин Ю. Н., Барахов В. М. Математическое моделирование и управление манипуляторами, как стержневыми системами переменной конфигурации // Вестник машиностроения. - Ульяновск: УлГТУ, 2007. - № 3. - С. 28-33.

5. Experimental results for the end-effector control of a single flexible robotic arm / Y. Aoustin, C. Chevallereau, A. Glumineau, C.H. Moog // IEEE Trans. Control Syst. Technol. -1994. -Vol. 2, No. 4. - P. 371-381.

6. Approaches for Dynamic Modeling of Flexible Manipulator Systems / J. M. Martins, Z. Mohamed, M.O. Tokhi, J. Sa'da Costa, M. A. Botto // IEEE Proc. Control Theory Appl. 2003. - Vol. 150, No. 4. - P. 401-411.

7. Leronid Reznik, Omar Ghanayem, and Anna Bourmistrov, "PID pulse fuzzy controller structures as a design for industrial application," Engineering Application of Artificial Intelligence, vol.13, no.4, pp.419-430, 2002.

8. Fuchun Sun, Lingbo Zhang, Yuangang Tang, and Jianwei Zhang"Neural Network plus Fuzzy PD Control of Tip Vibration for Flexible-link Manipulators", Proceedings of International Conference on Intelligent Robots end Systems,2004, Sendal, Japan.

9. Ross C.T.F. Finite element techniques in structural mechanics.- West Sussex, UK: Albion Publishing Limited, 1996.

10.Keven M. Passino and Stephen Yurkovich, "Fuzzy Control," Addison Wesley Longnan, Inc., 1998.

11. R. P. Copeland and K. S. Rattan, "A fuzzy supervisor for PD control of unknown systems," IEEE International Symposium on Intelligent Control, pp.22-26, August, 1994.

The work was carried out at the college of Engineering. University of Mosul 